\title{
SATISFAÇÃO EM CUIDAR DE IDOSOS COM ALZHEIMER: PERCEPÇÕES DOS CUIDADORES FAMILIARES
}

Fabiana Cristina Vidigal', Roberta Fernanda Rogonni Ferrari', Daysi Mara Murio Ribeiro Rodrigues', Sonia Silva Marcon², Vanessa Denardi Antoniassi Baldissera3, Lígia Carreira ${ }^{4}$

${ }^{1}$ Enfermeira. Mestranda pela Universidade Estadual de Maringá. Maringá-PR-Brasil.

${ }^{2}$ Enfermeira. Doutora em Filosofia da Enfermagem. Universidade Estadual de Maringá. Maringá-PR-Brasil. ${ }^{3}$ Enfermeira. Doutora em Enfermagem Psiquiátrica. Universidade Estadual de Maringá. Maringá-PR-Brasil.

${ }^{4}$ Enfermeira. Doutora em Enfermagem. Universidade Estadual de Maringá. Maringá-PR-Brasil.

RESUMO: O objetivo deste estudo foi apreender as condições de satisfação de cuidadores familiares de idosos com Doença de Alzheimer no município de Umuarama-PR. Trata-se de um estudo de natureza qualitativa, descritivo e exploratório, realizado com oito cuidadores familiares. Os dados foram coletados no período de julho a setembro de 2013, por meio de entrevistas semiestruturadas realizadas no domicilio e após, submetidas à análise, da qual emergiram quatro categorias: a vivência com o cuidado permite desenvolvimento de habilidades, o provimento de bem-estar ao idoso permite satisfação para o cuidador familiar, a religiosidade favorece a satisfação em cuidar e demonstrar amor e gratidão por meio do cuidado favorece a satisfação do cuidador familiar. Os resultados apontaram que também existe satisfação no ato de cuidar, desmitificando o imaginário de que essa atividade é permeada apenas por insatisfação e sobrecarga.

DESCRITORES: Doença de Alzheimer; Idoso; Cuidadores; Satisfação pessoal.

\section{SATISFACTION IN CARING FOR OLDER ADULTS WITH ALZHEIMER'S: PERCEPTIONS OF THE FAMILY CAREGIVERS}

\begin{abstract}
This study aimed to ascertain the conditions of satisfaction of family caregivers for older adults with Alzheimer's Disease in the municipality of Umuarama in the Brazilian state of Paraná (PR). It is a qualitative, descriptive and exploratory study, undertaken with eight family caregivers. The data were collected in the period July - September 2013, through semistructured interviews held in the caregivers' homes and later subjected to analysis, from which four categories emerged: The experience with the care allows the development of skills; The provision of well-being to the older adult affords satisfaction to the family caregiver; Religiosity promotes satisfaction in caring; and Demonstrating love and gratitude through the care promotes the satisfaction of the family caregiver. The results indicated that satisfaction also exists in the act of caring, demystifying the imaginary that this activity is permeated only by dissatisfaction and overload.
\end{abstract}

DESCRIPTORS: Alzheimer's Disease; Older adults; Caregiver; Personal satisfaction.

\section{SATISFACCIÓN EN CUIDAR DE ANCIANOS CON ALZHEIMER: PERCEPCIONES DE LOS CUIDADORES FAMILIARES}

RESUMEN: El objetivo de este estudio fue aprender las condiciones de satisfacción de cuidadores familiares de ancianos con Enfermedad de Alzheimer en el municipio de Umuarama, PR. Es un estudio de naturaleza cualitativa, descriptivo y exploratorio, realizado con ocho cuidadores familiares. Los datos fueron obtenidos en el periodo de julio a septiembre de 2013, por medio de entrevistas semiestructuradas realizadas en domicilio $y$, después, sometidas al análisis, del cual resultaron cuatro categorías: la vivencia con el cuidado posibilita desarrollo de habilidades, el proveimiento de bienestar al anciano, trae satisfacción para el cuidador familiar, la religiosidad favorece la satisfacción en cuidar y demostrar amor y gratitud por medio del cuidado posibilita la satisfacción del cuidador familiar. Los resultados apuntaron que también hay satisfacción en el hecho de cuidar, desmitificando el imaginario de que esa actividad es permeada solamente por insatisfacción y sobrecarga.

DESCRIPTORES: Enfermedad de Alzheimer; Anciano; Cuidadores; Satisfacción personal. 


\section{INTRODUÇÃO}

O envelhecimento é um processo dinâmico, progressivo, irreversível e universal, caracterizado pela ocorrência de alterações bioquímicas, morfológicas e psicológicas que determinam mudanças funcionais no organismo ${ }^{(1)}$. O envelhecimento populacional ocorrido nas últimas décadas tem provocado aumento na prevalência de doenças crônicas e neurodegenerativas, como é o caso da Doença de Alzheimer (DA). Só no ano de 2010, estimou-se que mais de 35 milhões de pessoas estavam vivendo com esse tipo de doença ${ }^{(2)}$.

Responsável por aproximadamente 50-70\% de todas as demências, a DA é uma doença neurodegenerativa progressiva, com início insidioso que é comumente diagnosticada de acordo com critérios clínicos diferenciais ${ }^{(3)}$.

Há uma forte correlação entre o estágio de demência e a capacidade de realizar atividades da vida diária e, mesmo no estágio mais leve da doença, o desempenho nessas atividades está comprometido. Nas fases mais avançadas, ocorre também o declínio de capacidades funcionais, comprometendo a realização das atividades de vida diária, tornando o idoso dependente de cuidados $^{(2-3)}$.

Partindo desse pressuposto, o idoso com DA é cada vez mais dependente de cuidados, demandando necessidade de outra pessoa assumir o papel de cuidador, seja familiar ou não, que oferecerá assistência para suprir a incapacidade funcional, temporária ou definitiva ${ }^{(4)}$. Quando esse papel é assumido pela família, a pessoa que assume os cuidados é denominada de cuidador familiar.

Sabe-se que a escolha do cuidador familiar do idoso dependente, por iniciativa ou designação da família, está vinculada ao grau de parentesco, ao sexo e à proximidade física e afetiva. As atividades desenvolvidas pelo cuidador - em sua maioria, cônjuge, filho e demais parentes consanguíneos - incluem auxílio na realização de cuidados pessoais, comunicação, medicação, mobilização e acompanhamento a serviços de saúde, com o objetivo de manter ou recuperar a qualidade de vida da pessoa cuidada ${ }^{(5)}$.

A família é considerada, portanto, uma unidade primária de cuidado, composta por membros que interagem e se apoiam, mutuamente, na presença de problemas. $O$ surgimento de doença no âmbito familiar, entretanto, provoca alterações comportamentais em seus membros e o relacionamento entre eles é modificado, com tendência ao aprofundamento, ampliação ou rompimento de laços afetivos ${ }^{(6)}$.

Além dessa nova configuração familiar, a pessoa que assume o papel de cuidador está sujeita a produção de demandas de cuidados que afetam sua dimensão física, mental e social. Particularmente, a dependência psicofuncional do idoso com demência, ao modificar a rotina, a dinâmica e a relação de troca entre os membros da família, pela inversão de papeis, coloca uma série de demandas novas e inesperadas à família. O cuidador tem de superar muitos desafios para exercer com precisão seu papel sem, contudo deixar de lado sua vida emocional e social(7).

Atrelado a esse contexto, o cuidador familiar geralmente preocupa-se no desempenho satisfatório de suas funções. Nem sempre consegue sozinho, compreender que o bom cuidador é aquele que observa e identifica o que a pessoa pode fazer por si, avalia as condições e ajuda a fazer as atividades. Cuidar não é fazer pelo outro, mas ajudar o outro quando ele necessita, estimulando a pessoa cuidada a conquistar sua autonomia, mesmo que seja em pequenas atividades, isso requer paciência e tempo ${ }^{(3)}$.

No cenário das famílias que vivenciam a cronicidade das doenças com demandas de cuidados, como na DA, espera-se dos profissionais da saúde, dentre eles o enfermeiro, possua conhecimentos e desenvolva intervenções específicas, além de um trabalho efetivo de acompanhamento e educação das famílias atingidas $^{(6)}$. Para tanto, os profissionais precisam estar atentos aos aspectos da condição biopsicossocial do cuidador em prestar assistência ao idoso com essa doença, principalmente no que se refereà satisfação de cuidar(8).

Diante do exposto definiu-se como objetivo do estudo apreender as condições de satisfação no ato de cuidar, dos cuidadores familiares de idosos com DA, haja vista o prazer e contentamento resultante desta prática.

\section{MÉTODOS}

Estudo de natureza qualitativa, descritivo e exploratório, realizado no município de Umuarama, situado na região noroeste do estado 
do Paraná/Brasil, que tem uma população de 100.676 habitantes, dos quais 12.700 são idosos ${ }^{(9)}$.

Participaram da pesquisa oito cuidadores familiares que atendiam aos seguintes critérios de inclusão: ser cuidador familiar de idoso com Doença de Alzheimer há mais de seis meses, ter capacidade cognitiva para responder aos questionários, obtendo pontuação mínima de 24 pontos na avaliação cognitiva do Mini Exame do Estado Mental (MEEM) ${ }^{(10)}$, possuir 18 anos ou mais e residir na cidade de Umuarama-PR.

Foi utilizada amostragem intencional, obtida a partir da visita de uma das pesquisadoras a três equipes de Estratégia de Saúde da Família (ESF) e um Centro de Saúde Escola (CSE) no município. Na seleção dos participantes contou-se com a colaboração dos Agentes Comunitários de Saúde (ACS), que indicaram os idosos com DA que eram cuidados por familiares.

Dos onze cuidadores elegíveis, dois não foram encontrados no domicílio após três tentativas e um não apresentou escore mínimo no Mini Exame do Estado Mental, de modo que participaram da pesquisa, oito idosos e seus respectivos cuidadores.

O contato inicial com o cuidador foi realizado por meio de visita domiciliar (VD) da pesquisadora, juntamente com o Agente Comunitário de Saúde responsável pela área adstrita. Os participantes foram informados sobre os objetivos do estudo, e em caso de concordância, era agendada a entrevista de acordo com a disponibilidade do pesquisador e do entrevistado.

Os dados foram coletados no período de julho a setembro de 2013, utilizando entrevista semiestruturada com questões abertas e aplicação de dois instrumentos: ficha de caracterização sociodemográfica aplicada aos cuidadores para obtenção de dados relacionados à idade, sexo, estado civil, grau de parentesco com o familiar, escolaridade e características da atividade de cuidar e o Índice de Barthel ${ }^{(11)}$ aplicado ao idoso, objeto de cuidado desses cuidadores.

Esse índice foi utilizado para verificar o nível de dependência dos idosos nas atividades de vida diária, tais como: comer, higiene pessoal, uso dos sanitários, tomar banho, vestire despir, controle de esfíncter, deambular e subir e descer escadas. A pontuação da escala varia de 0 a 100, em que 0 corresponde à máxima dependência $\mathrm{e}$
100 equivale à independência total.

A entrevista teve, como questão norteadora: "Fale-me a respeito do que é ser cuidador de um idoso com DA e sobre sua percepção dos aspectos positivos e gratificantes no ato de cuidar desse idoso?".

O tempo médio de duração de cada entrevista foi de 40 minutos, todo o conteúdo foi gravado em aparelho MP3 player e após transcritos no Microsoft Word 2010, dados relacionados ao Índice de Barthel foram tabulados e analisados em planilha do Exce/® utilizando a técnica descritiva.

$\mathrm{Na}$ sequência, os depoimentos foram transcritos na integra e após, submetidos à análise de conteúdo, modalidade Temática ou Categorial|(12). O ponto de partida da análise foi a identificação das hipóteses estabelecidas e a compreensão do que estava por trás de cada conteúdo manifesto ${ }^{(13)}$.

Em seguida, procedeu-se a análise e interpretação dos conteúdos obtidos, resultando no reconhecimento do tema, unidade de significação, que descodificou os núcleos de sentido da comunicação. A análise temática permitiu, portanto, descobrir a presença ou frequência de aparição do tema relacionado ao objetivo analítico do estudo ${ }^{(12)}$.

Esta pesquisa foi aprovada pelo Comitê de Ética em Pesquisa com Seres Humanos da Universidade Paranaense - UNIPAR, sob o parecer $n^{\circ} 335.501$, de acordo com o previsto na Resolução 466/12 do Conselho Nacional de Saúde e os participantes assinaram o Termo de Consentimento Livre e Esclarecido (TCLE), após receberem informações sobre os objetivos da pesquisa. Para garantir o sigilo e preservar a identidade dos cuidadores, os depoimentos foram identificados pela letra $C$ - por ser a inicial de cuidador, seguidos do número que indicava a ordenação da entrevista - (C1, C2, C3...C8).

\section{RESULTADOS}

Entre os cuidadores entrevistados, todos eram do sexo feminino e tinham idade mínima de 42 anos, com destaque para dois cuidadores com mais de 60 anos, evidenciando a tendência cada vez maior de idosos cuidando de outros idosos. Isso é preocupante, pois o cuidador idoso também possui condições de fragilidade 
inerentes ao processo de envelhecimento. A maior parte das cuidadoras eram filhas dos idosos com DA, católicas, coabitavam com eles, prestavam o cuidado há mais de dez anos e tinham escolaridade média de 7,5 anos de estudo.

Em relação ao estado civil, três eram casadas, três solteiras e duas divorciadas, constituindo um grupo heterogêneo. Todas relataram possuir acesso ao Sistema Único de Saúde (SUS) por meio das unidades de saúde instaladas, em seus respectivos bairros de moradia.

Todos os idosos que participaram da pesquisa eram portadores de DA e tinham idade superior a 60 anos. Quanto aos resultados obtidos com o índice de Barthel, três idosos possuíam dependência total, dois dependência grave, um com dependência moderada e dois idosos dependência leve, constituindo um grupo que necessitava de assistência constante do cuidador em suas atividades durante o dia, seja ela para realizar, auxiliar ou supervisionar.

A partir da identificação das unidades de registro realizaram-se o agrupamento dos temas em quatro categorias, a seguir apresentadas:

\section{A vivência com o cuidado permite desenvolvimento de habilidades.}

O envelhecer com DA significa uma vivência entremeada por limitações e fragilidades, que exigem dos cuidadores aprendizado contínuo e desenvolvimento de habilidades pessoais e competências técnicas relacionadas à aquisição de novos conhecimentos e comportamentos, conforme evidenciado nos discursos a seguir:

A gente aprende muito, eu não sabia cuidar, fui aprenderquando a internei, prestei atenção no que as enfermeiras faziam, e agora faço em casa [...]. (C1)

Tinha um parente que ajudava, ela cuidava do meu pai e me ensinou bastante, porque antes eu não sabia fazer muita coisa[...].(C2)

[...] muita coisa você tem que aprender, eu deixei a minha vida de lado para viver em função da dela. (C4)

Eu tive que aprender a cuidar, procuro fazer uma rotina diária de suas atividades básicas como comer, tomar banho e outras que sei serem necessárias, como tomar sol e caminhar no quintal. Também leio pra ele, desta forma eu acredito que ele se sente mais seguro e menos aborrecido [...]. (C6)

O reconhecimento pelo cuidador familiar de seu papel no enfrentamento da doença favorece o desenvolvimento de competências técnicas e habilidades pessoais, como uma forma de aprendizado na prestação do cuidado.

[...] primeiro precisei aprender muita coisa, aprendi a ter muita paciência, porque você passa o dia todo se repetindo, que precisa ser resiliente e percebe então que tem que manter a calma, não mudar o seu tom de voz, tenta manter o foco, porque do contrário fica muito difícil, então você aprende acima de tudo, que quem está assim, não é porque quer. Então, aprende a ter calma e a ser paciente [...]. (C3)

Mais tive que aprender muita coisa para poder cuidar bem da minha mãe, fazer curativo quando ela teve ferida, fazer massagem para aliviar a dor nas costas dela, dar os remédios certos no horário certo. (C5).

Eu cresci muito, aprendi muita coisa, primeiro a controlar meus sentimentos, depois os cuidados específicos para a doença dele [...]. (C8)

\section{O provimento de bem-estar ao idoso permite satisfação para o cuidador familiar}

Conhecer e reconhecer a subjetividade de cuidar tornou-se essencial no processo do cuidado humanizado realizado pelo cuidador familiar tanto na dimensão instrumental como expressiva. A dimensão expressiva do cuidado caracterizou-se pela natureza emocional, resultando em interações que permitiram a expressão de sentimentos relacionados à experiência ou à vivência no processo saúdedoença, incluindo a intuição da subjetividade. Os cuidadores relataram prazer em poder proporcionar o bem estar ao ente querido, foco de seus cuidados, destacando o banho como um 
dos cuidados que mais lhes dava contentamento.

No fundo você tem muito prazer, meu maior prazer é quando acabo de dar banho nela, eu dou banho, troco e passo talco, é a mesma coisa de dar banho em um bebe e deixar cheiroso [...]. (C4).

[...] apesar de ser difícil, eu gosto de cuidar dela, me dá muita satisfação saber que ela precisa de mim e de todos os cuidados que faço diariamente. É tão bom quando termino de dar o banho, gosto de deixar ela mais confortável e feliz, pois isso diminui a irritação dela. (C5).

Quando termino de dar banho nela, ela me dá um abraço e um beijo todas às vezes e me diz muito obrigada. Percebo que quando ela sai do banho ela fica mais feliz, depois do banho tomo um café da tarde com ela e ficamos horas conversando sobre as histórias de quando ela era moça [...]. (C7)

É gratificante saber que hoje ela ainda está viva e agora sou eu que posso cuidar dela, dar todo amor, carinho, atenção e dedicação dados a mim um dia, e que ela com toda certeza merece hoje. (C6)

\section{A religiosidade favorece a satisfação em cuidar}

A doença traz consigo muitas vezes, sofrimento, solidão e vulnerabilidade, sentidos não só pelos pacientes, mas especialmente por seus cuidadores, que buscam refugio em suas experiências religiosas e espirituais. As falas a seguir refletem esta realidade:

É uma oportunidade que a gente tem de saber que se Deus nos der a alegria de chegar à idade que ela está, o que estamos semeando hoje, por exemplo, se estamos amando hoje, com certeza seremos amados e respeitados no futuro também. (C3).

Tem muitos aspectos positivos em poder cuidar do meu pai que tem Alzheimer, primeiro que eu me sinto a vontade quando faço todos os cuidados, eu gosto de fazer isso, eu gosto de ajudar os outros, eu me identifico por isso me sinto muito feliz em poder cuidar dele, e quero cuidar até quando Deus me der saúde, pois assim eu posso cumprir a minha missão aqui na terra. Eu sei que todo mundo tem uma missão independente de sua fé, às vezes mais fácil, outras vezes mais difícil, mas todo mundo tem uma. Eu já reconheci a minha, que é cuidar do meu pai que tem essa doença que vai deixando ele mais fraco a cada dia. (C6).

A resiliência fortalecida pela fé é uma constante sentida na vida dos cuidadores familiares primários de idosos com Doença de Alzheimer, principalmente no que diz respeito à satisfação em prestar o cuidado.

\section{Demonstrar amor e gratidão por meio do cuidado favorece a satisfação do cuidador familiar}

A doença extrapola o evento biológico em si, pois é uma construção sociocultural que possui diferentes significados e interpretações de acordo com quem a vivencia, interferindo nas relações interpessoais, principalmente dentro da família. No contexto familiar, a pessoa que assume o papel de cuidador, já está de certa forma adaptada a viver a vida de outra pessoa. Verifica-se que não só o paciente se torna dependente do cuidador, mas também estabelece vínculo tão íntimo com o paciente, que cuidar lhe proporciona prazer, bem estar, satisfação e contentamento. As falas, a seguir, demonstram todo o amor e gratidão existentes no ato de cuidar em reconhecimento a importância e relevância que o familiar cuidado já teve na vida do cuidador.

[...] às vezes eu entro no quarto e percebo que é a mim que ela procura com os olhos, ela está na cadeira aqui e eu fazendo almoço, ela fica me procurando, me chama toda hora, eu acordo com ela e isso pra mim é tudo, muito gratificante [...]. (C1)

Comecei a cuidar da minha mãe por minha própria vontade mesmo, porque ela cuidou dos meus dois filhos, a minha filha mais velha ela quem criou, e do meu filho ela que cuidou, não precisaram ficar na creche graças a ela, então de certa maneira eu estou retribuindo. Ë uma forma de reconhecer que ela é a minha mãe [...]. (C2)

Poder cuidar do meu pai é muito bom, pois ele cuidou de mim quando eu era pequena e agora 
chegou a hora de eu retribuir a ele todo esse amor. É um prazer poder cuidar dele, porque ele é meu pai, e merece o melhor de mim.Cuidar dele e retribuir o que ele fez por mim, é meu dever[...]. (C8)

Cuidar é uma forma de gratidão, expressa por meio de sentimentos ou ações, manifestos nas falas dos cuidadores familiares de idosos com DA. Trata-se de subjugar o próprio eu para satisfazer os desejos e necessidades do outro.

Como ela cuidava de mim, eu cuidei das minhas filhas e agora eu também cuido dela [...]. (C4)

Cuidar do meu pai é maravilhoso, porque ele sempre foi muito bom com todas as pessoas, se não fosse ele, não sei como a minha vida seria. (C5)

A minha maior satisfação é saber que eu estou sempre perto do meu pai, conheço como ele gosta da comida, como gosta de tomar banho, como gosta de se vestir, posso cuidar melhor dele especialmente por conhecer o gosto dele. Eu amo o meu pai e ele me ama. (C6)

\section{DISCUSSÃO}

Os problemas de saúde decorrentes da DA exigem cuidados criteriosos e intensos dos cuidadores, favorecendo o desenvolvimento de habilidades pessoais. Acrescente-se a isso, os problemas de saúde típicos do envelhecimento que contribuem, direta e indiretamente, à fragilidade do idoso ${ }^{(14)}$.

A auto percepção da família no exercício do cuidado ativo, além de proporcionar bem estar ao ente querido, foi capaz de desenvolver habilidades distintas no enfrentamento da DA e remete ao profissional de enfermagem o importante papel de ensinar esse cuidado. Uma das atribuições desempenhadas pela enfermagem, neste estudo, foi orientar os cuidadores familiares a compreenderem os indivíduos e sua condição atual, de modo que possam perceber que os comportamentos apresentados são decorrentes da doença, entendendo que a família é uma unidade que precisa ser reconhecida como extensão da enfermagem na prestação dos cuidados e autocuidados ${ }^{(15)}$. Cabe à enfermagem o olhar atento na identificação das dificuldades do cuidador na execução de seu trabalho, atuando como educador, multiplicador e facilitador das informações de ações de saúde ${ }^{(16)}$.

O estudo evidenciou que o processo de envelhecimento acompanhado de uma doença debilitante como a DA, prejudica funcionalmente os idosos, tornando-os cada vez mais dependentes na realização de atividades como vestir-se, alimentar-se, tomar banho, administrar medicamentos e outras tarefas, que acabam sendo realizadas por terceiros, normalmente por cuidadores informais representados por um membro familiar ${ }^{(17-18)}$.

É no seio familiar que são transmitidos os valores morais e sociais que servirão de base para o processo de socialização do ser humano, bem como as tradições e os costumes perpetuados através de gerações. Em situações em que o envelhecimento é aceito como êxito e aproveitamento da competência, o cuidador familiar tende a sentir-se satisfeito em beneficiar alguém que um dia dispôs a própria vida pela sua ${ }^{(1)}$.

O estudo aponta que o cuidador familiar reconhece que o idoso com DA, objeto de seu cuidado, merece atenção, carinho e amor, manifestos de forma desinteressada em reconhecimento a toda abnegação e dedicação um dia proporcionados a eles. A satisfação do cuidado está na retribuição e gratidão de todo amor recebido ao longo de uma vida ${ }^{(17)}$.

A nova realidade no cotidiano dos cuidadores familiares de idosos com DA traz a necessidade de estratégias de adaptações, entre as quais se destacam a religião. Essa atitude é demonstrada por meio de orações e no exercício da paciência, atribuindo a suas crenças a esperança de melhoria da experiência vivida ${ }^{(5)}$. Para o cuidador, a religiosidade passa a representar uma importante fonte de suporte emocional, que repercute de forma significativa em sua saúde mental e física $^{(19-20)}$. Além disso, a própria vivência com a doença crônica e a condição de cuidador impõe reflexão e, geralmente, ressignificação da vida pela experiência, encontrando alento na religiosidade.

Estudos realizados com cuidadores de idosos com DA evidenciaram capacidades distintas com que os membros da família enfrentam a doença ${ }^{(18,21)}$. A percepção do respeito à autonomia e à dignidade 
de cada um é imperativo ético no discurso dos cuidadores em favor do que pode ou não ser realizado uns pelos outros, haja vista a preocupação em satisfazer as necessidades do próximo, de tal forma que se sintam felizes em fazê-lo ${ }^{(14)}$.

A auto percepção da impossibilidade de atuarem ativamente na cura da doença permite aos cuidadores a satisfação de contribuírem no processo de amenização do sofrimento de seus familiares. Ressalta-se que os achados deste estudo contrapõem-se aos de outros estudos, em que os discursos dos cuidadores expressam resignação, aceitação e sofrimento ao terem de conviver com um familiar com DA ${ }^{(7,14,18,21)}$. Um resultado peculiar deste estudo foi a ausência de sentimentos de revolta, sobrecarga e não aceitação da doença crônica do idoso, pois embora os informantes tenham sido solicitados a indicarem os aspectos positivos e gratificantes de cuidar, eles também tiveram oportunidade de se manifestarem sobre o que é ser cuidador familiar de idoso com DA.

\section{CONSIDERAÇÕES FINAIS}

Nesse estudo, observou-se que a realidade dos cuidadores familiares foi entremeada da satisfação em garantir os cuidados necessários para se alcançar a amenização do sofrimento e equilíbrio em meio à adversidade, através da crença e fé permeada de um olhar de esperança. Cuidar de um familiar com doença crônica permitiu aos cuidadores familiares aprenderem a desenvolver habilidades pessoais e competências técnicas, que culminaram na satisfação da expressão de amor e carinho em forma do cuidado.

Intervenções individuais que disponibilizem orientações e educação sobre como realizar o cuidado de modo apropriado, aliadas a políticas públicas que viabilizem adequada rede social de apoio e suporte da atenção primária em saúde, são de extrema relevância no reconhecimento do trabalho desempenhado pelos cuidadores familiares, considerando a redução no tamanho dos núcleos familiares e a falta de mão de obra qualificada para atender à demanda crescente de idosos dependentes, morando no próprio domicílio e o provável crescimento de filhos, netos e cônjuges responsabilizados pelo cuidado domiciliário.

\section{REFERÊNCIAS}

1. Moreira PL, Villas Boas PJF,Ferreira ALA. Associação entre estresse oxidativo e estado nutricional em idosos. Rev. Assoc. Med. Bras.[Internet] 2014; 60(1) [acesso em 10 abr 2013]. Disponível: http://dx.doi. org/10.1590/1806-9282.60.01.016

2. Santos JG, Andrade LP, Pereira JR, Stein AM, Pedroso RV, Costa JLR. Análise de protocolos com intervenção motora domiciliar parágrafo pacientes com doença de Alzheimer:uma revisão sistemática. Rev. bras. geriatr. gerontol. [Internet] 2013; 16(3) [acesso em 11 ago 2013]. Disponível: http://dx.doi.org/10.1590/S180998232013000300018

3. Talmelli LFS, Vale FAC, Gratão ACM, Kusumota L, Rodrigues RAP. Doença de Alzheimer: declínio funcional e estágio da demência. Acta Paul. Enferm. [Internet] 2013; 26(3) [acesso em 17 ago 2013]. Disponível: http://dx.doi.org/10.1590/S010321002013000300003

4. Borghi AC, Sassá AH, Matos PCB, Decesaro MN, Marcon SS. Qualidade de vida de idosos com doença de Alzheimer e de seus cuidadores. Rev. gauch. enferm. [Internet] 2011; 32(4) [acesso em $10 \mathrm{mar}$ 2013]. Disponível: http://dx.doi.org/10.1590/S198314472011000400016

5. Menezes MR, AlvesMB, SouzaAS, Silva VA, Silva EN, Oliveira CMS. Comportamento agressivo na relação entre idoso e cuidador familiar em doenças demenciais. Cienc cuid saúde [Internet] 2013; 12(4) [acesso em 15 out 2013]. Disponível: http://dx.doi. org/10.4025/cienccuidsaude.v12i4.19529

6. KandaMH, Contim D, Gonçalves JRL, Santos EA. A percepção dos familiares cuidadores sobre o tratamento quimioterápico em crianças e adolescentes. Cogitare enferm. [Internet] 2014; 19(1) [acesso em 19 abr 2014]. Disponível: http://ojs.c3sl.ufpr.br/ojs/index. php/cogitare/article/viewFile/35962/22171

7. Oliveira APP, Caldana RHL. As repercussões do cuidado na vida do cuidador familiar do idoso com demência de Alzheimer. Saúde soc. [Internet] 2012; 21(3) [acesso em 10 set 2013]. Disponível: http://dx.doi. org/10.1590/S0104-12902012000300013

8. Perez GB. A família como sujeito do cuidado. Aquichán [Internet] 2013; 13(1) [acesso em 23 jun 2013]. Disponível: http://www.scielo.org.co/scielo.php?script=sci_ arttext\&pid=S1657-59972013000100001

9. IBGE - Instituto Brasileiro de Geografia e Estatística. Censo Demográfico 2010. Rio de Janeiro/RJ, 2011. [Internet] [acesso em 13 set 2013]. Disponível:http:// cidades.ibge.gov.br/xtras/perfil

10. Bertolucci PHF, BruckiS MD, Campacci SR, Juliano Y. 
O mini exame do estado mental em uma população geral: impacto da escolaridade. Arq. neuro-psiquiatr. 1994; 52(1): 1-7.

11. Mahoney F, Barthel D, (1965). Functional Evolution. Ed. Med. J. p. 61-65.

12. Gomes R. Análise e interpretação de dados de pesquisa qualitativa. In: Minayo MCS, organizadora. Pesquisa Social: teoria, método e criatividade. Rio de Janeiro: Vozes; 2011. p. 79-106.

13. Minayo MCS. O desafio do conhecimento: pesquisa qualitativa em saúde. $11^{a}$ ed. São Paulo: Editora Hucitec; 2010.

14. Wachholz PA, Santos RCC, Wolf LSP. Reconhecendo a sobrecarga e a qualidade de vida de cuidadores familiares de idosos frágeis. Rev. bras. geriatr. gerontol. [Internet] 2013; 16(3) [acesso em 22 set 2013]. Disponível: http://dx.doi.org/10.1590/S180998232013000300010

15. Alves SGS, Vasconcelos TC, Miranda FAN, Costa TS, Sobreira MVS. Aproximação à subjetividade de enfermeiros com a vida: afetividade e satisfação em foco. Esc. Anna Nery [Internet] 2011; 15(3) [acesso em 17 mai 2013]. Disponível: http://dx.doi.org/10.1590/ S1414-81452011000300010

16. Carbone G, Barreca F, Mancini G, Pauletti G, Salvi V, Vanacore $\mathrm{N}$. et al. Um modelo de assistência domiciliar para a demência: resultados em pacientes com doença de Alzheimer leve a moderada após três meses. Ann. Ist. Super. Sanità [Internet] 2013; 49(1) [acesso em 9 jun 2013]. Disponível: http://dx.doi.org/10.4415/ANN_13_01_07

17. Reis LA, Santos KT, Reis LA, Gomes NP. Qualidade de vida e fatores associados para cuidadores de idosos funcionalmente prejudicados. Rev. Bras. Fisioter. [Internet] 2013; 17(2) [acesso em 22 jul 2013]. Disponível: http://dx.doi.org/10.1590/S141335552012005000078

18. Borghi AC, Castro VC, Marcon SS, Carreira L. Sobrecarga de familiares cuidadores de idosos com doença de Alzheimer: um estudo comparativo. Rev. Latino-Am. Enfermagem [Internet] 2013; 21(4) [acesso em set 2013]. Disponível: http://dx.doi.org/10.1590/ S0104-11692013000400007

19. Sousa RF. Religiosidade no Brasil. Estud. av. [Internet] 2013; 27(79) [acesso em 3 jul 2013]. Disponível: http:// dx.doi.org/10.1590/S0103-40142013000300022

20. Zenevicz L, Moriguchi Y, Madureira VSF. A religiosidade no processo de viver envelhecendo. Rev. Esc. Enferm. USP [Internet] 2013; 47(2) [acesso em $21 \mathrm{abr}$ 2013]. Disponível: http://dx.doi.org/10.1590/S008062342013000200023

21. Manoel MF, Teston EF, Waidman MAP, Decesaro
MN, Marcon SS. As relações familiares e o nível de sobrecarga do cuidador familiar. Esc. Anna Nery [Internet] 2013; 17(2) [acesso em 10 jun]. Disponível: http://dx.doi.org/10.1590/S1414-81452013000200020 